\title{
PIRANDELLO E A INQUIETUDE MODERNA
}

\author{
Andrea Quilian de Vargas \\ Rosani Úrsula Ketzer Umbach \\ UFSM/CAPES/CNPq
}

RESUMO: 0 escritor e dramaturgo siciliano Luigi Pirandello viveu entre dois mundos: 0 atrasado universo da Sićlía no final do século XIX, e a arrojada modernidade do início do XX. Sua obra contempla as mutações dos sistemas de valores e a transformação das condições sociais e históricas da vida, ao mesmo tempo em que ressalta a impotência do homem diante dessa realidade. Sua poética se articula segundo a dinâmica e a temática de uma estética decadentista que critica a sociedade e os postulados de um radicalismo artístico, assim como a ausência de sentido da história e da vida. 0 falecido Mattia Pascal, Um, nenhum e cem mil, Seis personagens à procura de um autor e Assim é (se lhe parece) são obras citadas neste trabalho com 0 intuito de mostrar que fragmentação, ruptura com a mimesis e antirrepresentação são uma constante em Pirandello, cuja obra se encontra imersa na contraditória modernidade.

PALAVRAS-CHAVE: Pirandello. Modernidade. Antirrepresentação.

\section{PIRANDELLO AND THE MODERN UNEASINESS}

ABSTRACT: The Sicilian writer and playwright Luigi Pirandello lived between two worlds: the late Sicily universe in the end of the nineteenth century, and the bold modernity in the beginning of the twentieth century. His work encompasses the changes in the system of values as well as the social and historical transformations. At the same time, he highlights the powerless man who was facing such reality and this becomes a meaningful element in his texts. Pirandello's poetic constitutes itself according to the dynamics and theme of a criticizing decadence towards society, the postulates of an artistic radicalism and the absence of history, and life meaning as well. 0 falecido Mattia Pascal, Um, nenhum e cem mil, Assim é (se lhe parece) e Seis Personagens à Procura de um Autor are the works cited in this paper with the purpose of showing that fragmentation, mimesis dissuption and anti-representation are constant in Pirandello's works which are immersed in the contradictory modernity.

KEYWORDS: Pirandello. Modernity. Anti-representation.

é doutoranda em Estudos Literários na Universidade Federal de Santa Maria.

é professora titular do Departamento de Letras Estrangeiras Modernas da Universidade Federal de Santa Maria. 


\title{
PIRANDELLO E A INQUIETUDE MODERNA
}

\author{
Andrea Quilian de Vargas \\ Rosani Úrsula Ketzer Umbach
}

Não me parece mais, o atual, tempo de escrever livros, nem por brincadeira. No que diz respeito à literatura, como a tudo o mais, devo repetir meu costumeiro estribilho: "Maldito seja Copérnico!"

Pirandello, O falecido Mattia Pascal

Tentar compreender a obra de Pirandello em sua totalidade é adentrar uma prática discursiva inserida em um problemático contexto: a modernidade. Recordemos alguns importantes eventos históricos da época que abrange desde o nascimento (1867) até a morte (1936) do escritor e dramaturgo siciliano, sem os quais o mundo econômico, social e cultural não seria como o conhecemos. A história moderna é marcada, segundo o escritor e filósofo estadunidense Marshall Berman (1982, p. 15), por grandes descobertas nas ciências físicas, descomunal explosão demográfica, desenvolvimento de sistemas de comunicação, Estados nacionais cada vez mais poderosos que lutam com obstinação para expandir seu poder, movimentos sociais de massa e de nações lutando para obter algum controle. Em Tudo que é sólido desmancha no ar, Berman afirma que:

Ser moderno é encontrar-se em um ambiente que promete aventura, poder, alegria, crescimento, autotransformação e transformação das coisas em redor mas ao mesmo tempo ameaça destruir tudo o que temos, tudo o que sabemos, tudo o que somos. A experiência ambiental da modernidade anula todas as fronteiras geográficas e raciais, de classe e nacionalidade, de religião e ideologia: nesse sentido, pode-se dizer que a modernidade une a espécie humana. Porém, é uma unidade paradoxal, uma unidade de desunidade: ela nos despeja a todos num turbilhão de permanente desintegração e mudança, de luta e contradição, de ambiguidade e angústia. Ser moderno é fazer parte de um universo no qual, como disse Marx, "tudo o que é sólido desmancha no ar". ${ }^{1}$

\footnotetext{
${ }^{1}$ BERMAN, Marshall. Tudo que é sólido desmancha no ar. A aventura da modernidade. Trad. Carlos Felipe Moisés e Ana Maria L. Ioriatti. São Paulo: Companhia das Letras, 1986, p. 15.
} 
Esse conjunto de fatores criou um estado de consciência histórica, crítica e filosófica oscilante, sendo a "decadência"² a ideologia predominante da modernidade. Em sentido negativo, significou um estado de crise da razão e da consciência ligada a fenômenos como a alienação social do indivíduo e a degradação dos valores humanos, grosso modo. Em sentido positivo, a decadência configurou-se como resposta artística a essa crise por intermédio de obras de escritores obstinados como Huysmans, no contexto francês, e Pirandello, no caso da Itália. Este se insere nos moldes decadentistas ao ressaltar como elemento significativo em seus textos o homem alienado e impotente. Nesse sentido, a obra de Pirandello se articula segundo a dinâmica e a temática de uma decadência que critica a sociedade e os postulados de um radicalismo artístico, assim como a ausência de sentido da história. É moderna, da mesma forma, na medida em que contempla as mutações dos sistemas de valores e a transformação das condições sociais e históricas da vida.

Em Tudo que é sólido desmancha no ar, Marshall Berman divide a modernidade em três fases, sendo que a primeira compreende o período entre o início do século XVI e o fim do século XVIII, quando as pessoas não fazem ideia do que as estava atingindo. A segunda fase começa com a onda revolucionária de 1870 e com as reverberações da Revolução Francesa, a qual instaurou um espírito revolucionário que desencadeou explosivas convulsões em todos os níveis de vida pessoal, social e política. Todavia, o público moderno do século XIX ainda mantinha vínculos com um mundo que não chegava a ser moderno na sua totalidade. "É dessa profunda dicotomia, dessa sensação de viver em dois mundos simultaneamente, que emerge e se desdobra a ideia de modernismo e modernização." ${ }^{3}$ Para Berman:

Na terceira e última fase, no século $X X$, o processo de modernização se expande a ponto de abarcar virtualmente o mundo todo, e a cultura mundial do modernismo em desenvolvimento atinge espetaculares triunfos na arte e no pensamento. Por outro lado, à medida que se expande, o público moderno se multiplica em uma multidão de fragmentos, que falam linguagens incomensuravelmente confidenciais; a ideia de modernidade, concebida em inúmeros e frag-

\footnotetext{
${ }^{2}$ Inspirado na poética revolucionária de Charles Baudelaire e como oposição à cientificidade do Realismo e do Naturalismo, o Decadentismo surge, no final do século XIX, como uma sensibilidade estética contrária às associações frequentes entre arte, objeto e técnica, que evocava a evasão à realidade cotidiana, a exaltação dos elementos ligados à ruína social e moral, a morte, o tédio, associados à crença de que as regras do dia-a-dia não mais tinham aplicação no campo das artes.

${ }^{3}$ BERMAN, Marshall. Tudo que é sólido desmancha no ar, op. cit., p. 15.
} 
mentários caminhos, perde muito de sua nitidez, ressonância e profundidade, e perde sua capacidade de organizar e dar sentido à vida das pessoas. ${ }^{4}$

Inserido nesse contexto, o microcosmo das novelas, dos romances e do teatro pirandellianos é a forma compactada de certo conjunto de comportamentos levados ao paroxismo, pois Pirandello é um autor que identifica com grande clareza as causas sociais e históricas da alienação do indivíduo que vivencia a modernidade sem entendê-la claramente. Segundo afirma Aurora Fornoni Bernardini, em Henrique IV e Pirandello, ele mesmo viveu:

no limiar de duas épocas, duas concepções de mundo, indiscutivelmente contrastantes - faltou-lhe, no dizer de alguns críticos, o salto da dialética para integrá-las, viveu os momentos do drama sem resolvê-lo, e mesmo que no fim [...] tenha esboçado os caminhos de uma metafísica [...], permaneceu, contudo, basicamente preso ao fio sutil de uma pungente saudade por tudo o que foi passando sem poder deter-se, de tudo que foi sendo sem conseguir viver. ${ }^{5}$

Desse modo, suas personagens encontram-se absorvidas por um emaranhado de conflitos entre o presente e o passado, o social e o individual, a vida e a arte, o ser e o parecer. Nesse sentido, toda sua poética repousa sobre a tentativa de ruptura da antiga relação entre a denotação e a conotação, tematizada seja formalmente, seja ideologicamente. A quebra da harmonia entre autor e personagem, personagem e ator, representação e vida, pessoa e personagem, representa formalmente a indagação acerca do sentido da vida e da arte que ronda toda a obra de Pirandello.

Em seus textos são sublinhadas a crise dos valores burgueses (como o individualismo), a instabilidade das instituições sociais (especialmente a família e o casamento), a imutabilidade da natureza humana, a antiga relação aparentemente indissolúvel entre significantes e significados, resumida na afirmação: “Assim é, se lhe parece". É importante reconhecermos, entretanto, que mesmo que o dialogismo pirandelliano pressuponha temáticas dominantes (a crise do sujeito, a multiplicidade das máscaras, a incomunicabilidade), nem por isso Pirandello se coloca no interior dessas ideologias. Suas personagens são, por vezes, pensadores, por vezes vestígios da psicologia à maneira de Dostoiévski, mas, em cada caso, suas atitudes desestabilizam os componentes

\footnotetext{
${ }^{4}$ Ibidem, p. 15-16.

${ }^{5}$ BERNARDINI, Aurora Fornoni. Henrique IV e Pirandello. Roteiro para uma leitura. São Paulo: EDUSP, 1990, p. 17-18.
} 
da ideologia burguesa, sobretudo a ideia de um individualismo realizável e um mundo perfeito.

A queda da linguagem reduzida ao tom explicativo também deriva, em Pirandello, da consciência acerca da inautenticidade das máscaras e dos papeis sociais, os quais decompõem qualquer fundamento ou certeza. Assim sendo, o siciliano teatraliza, narrativiza e põe em discussão a desintegração, a queda do indivíduo moderno, incapaz de efetivar a própria individuação por não possuir um espaço que seja só seu. Sua subjetividade e sua consciência de si encontram obstáculos: os sistemas sociais institucionalizados.

São esclarecedores, para que entendamos melhor as conexões existentes entre Pirandello e a modernidade, alguns trechos de $O$ falecido Mattia Pascal. Publicado em 1904, o romance tem como protagonista um bibliotecário de uma perdida aldeiazinha no interior da Itália, Miragno, que vê seu nome na página necrológica do jornal local. Após ter passado alguns dias jogando em Monte Carlo, Mattia fora considerado desaparecido e, segundo o jornal, estava morto. O defunto havia sido encontrado nas suas terras e reconhecido pela esposa e a sogra, com quem Mattia havia se desentendido antes da partida. Com oitenta e duas mil liras no bolso, uma importância de certo vulto na época, o atordoado protagonista leu na primeira página do jornal:

Suicídio: assim, em negrito. Ontem, sábado, 28, foi encontrado, na levada de uma azenha, um cadáver em estado de adiantada putrefação. [...] A azenha está localizada num sítio chamado da Stia, a cerca de dois quilômetros da nossa cidade. [...] Mais tarde, foi reconhecido como o nosso [...] bibliotecário Mattia Pascal, desaparecido há vários dias. Causa do suicídio: dificuldade financeira. ${ }^{6}$

Inicialmente, a vontade de Mattia foi desfazer aquela mentira absurda, mandar logo um telegrama dizendo que ele estava voltando, que continuava vivo. Mas não foi isso que o confuso bibliotecário fez:

[...] mas claro! Minha libertação, a liberdade, uma nova vida! [...] Estava morto, estava morto, não tinha mais dívidas, não tinha mais mulher, não tinha mais sogra, ninguém! Livre, livre, livre! Que pretendia mais? ${ }^{7}$

A partir daí, Mattia Pascal, "o falecido", mergulhou na construção de uma

\footnotetext{
${ }^{6}$ PIRANDELLO, Luigi. O falecido Mattia Pascal; Seis personagens à procura de um autor. Trad. Mário da Silva, Brutus Pedreira e Elvira Rina. São Paulo: Abril Cultural, 1981, p. 97-98.

7 Ibidem, p. 100.
} 
nova identidade, batizada, mais tarde, com o nome de Adriano Meis. "Uma identidade se esvai, outra surge". ${ }^{8}$ Sobre essa peripécia que inicia o romance de Pirandello, assim escreve Alfredo Bosi:

O romance mostra, nesse primeiro tempo, a possibilidade da morte da máscara social. Possibilidade que se revela, do meio para o fim da narração, como algo precário e afinal ilusório: a nova personagem, nascida do nada, e que recebera o nome de Adriano Meis, também começa a assumir, para os outros, uma determinada fisionomia pela qual será vista, julgada e cristalizada na teia social. A fôrma social é uma fonte de equívocos e sofrimentos, um mal insuperável. ${ }^{9}$

Em outra passagem do romance, logo após decidir não mais voltar para casa, Mattia se depara com um importante problema:

Quem é que ele [o cocheiro] está conduzindo? Nem mais eu mesmo sei. Quem sou eu, agora? É preciso que pense nisso. Um nome, pelo menos, um nome é indispensável que me dê a mim, sem demora, [...] para não me ver atrapalhado se, depois, na estalagem, me perguntarem qual é. [...] Vejamos! Como é que me chamo ${ }^{10}$

A modernidade de Pirandello, portanto, se projeta em um novo paradigma, aquele do indivíduo que mal pode suportar a própria máscara, mas que não é capaz de suplantá-la. Berman ratifica tal assertiva ao afirmar que "o homem moderno jamais se mostrará bem trajado, porque nenhum papel social nos tempos modernos é para ele um figurino perfeito. ${ }^{11}$ Mattia Pascal é, desse modo, a ficcionalização desse homem deslocado e abismado que reflete sobre a vida em tempos de modernidade:

Mas a vida, ao contemplá-la desse modo, como espectador, parecia-me, agora, sem substância e sem finalidade; sentia-me perdido naquela turbamulta. $E$, enquanto isso, o estardalhaço e a incessante agitação da cidade atordoavam-me. Mas, por que os homens, perguntava-me a mim mesmo febrilmente, afanam-se assim em tornar cada vez mais complicado o mecanismo de sua vida? Por que todo esse estrondo de máquinas? E o que fará o homem, quando as máquinas fizerem tudo? Compreenderá, então, que o chamado progresso nada tem a ver com a felicidade? Mesmo admirando-as, que alegria experimentamos por todas as invenções com as quais a ciência acredita honestamente que enriquece a

\footnotetext{
${ }^{8}$ BOSI, Alfredo. Céu, inferno. Ensaios de crítica literária. São Paulo: Editora Ática, 2002, p. 133.

${ }^{9}$ Idem.

${ }^{10}$ PIRANDELLO, Luigi. O falecido Mattia Pascal, op. cit., p. 102.

${ }^{11}$ BERMAN, Marshall. Tudo que é sólido desmancha no ar, op. cit., p. 21.
} 
humanidade (e a empobrece, porque custam tão caro) $?^{12}$

Marshall Berman assinala que, na modernidade do século XIX, destacam-se as novas paisagens, dinâmicas e desenvolvidas, repletas de engenhos a vapor, fábricas, apitos, ferrovias, áreas industriais desenvolvidas, jornais diários, telégrafos, telefones e, em especial, "um mercado mundial que a tudo abarca, em crescente expansão, capaz de um estarrecedor desperdício e devastação, capaz de tudo, exceto solidez e estabilidade". ${ }^{13}$ Esse ambiente é fortemente atacado pelos pensadores modernistas, os quais se esforçam para fazê-lo ruir, mesmo estando à vontade em meio a todo esse caos. Em outras palavras, havia uma oposição, mas articulada e pensada de forma positiva. Em Pirandello, todavia, é perceptível outra postura diante do turbilhão moderno, aquela defendida pelos críticos do século XX, os quais, segundo Berman:

carecem quase inteiramente dessa empatia com e fé em seus camaradas, homens e mulheres modernos. [...] não só a sociedade moderna é um cárcere, como as pessoas que aí vivem foram moldadas por suas barras; somos seres sem espírito, sem coração, sem identidade sexual ou pessoal - quase podíamos dizer: sem ser. Aqui, como nas formas futuristas e tecnopastorais do modernismo, o homem moderno como sujeito - como um ser vivente capaz de resposta, julgamento e ação sobre o mundo - desapareceu. ${ }^{14}$

Assim sendo, o desconforto diante do teor compulsório da vida transforma-se em tragédia social, reescrita em Pirandello por intermédio da impossibilidade de ser de suas personagens, sendo Vitangelo Moscarda um exemplo pertinente. Rico e ocioso banqueiro, o protagonista de Um, nenhum e cem mil, romance elaborado entre os anos 1916 e 1926, ao ouvir da esposa que seu nariz era torto, que suas orelhas não eram simétricas e que suas sobrancelhas mais pareciam dois acentos circunflexos, submerge em um processo que desnuda a fragilidade do Eu, em face do olhar do Outro. Moscarda descobre que somos para os outros tão somente aquilo que parecemos, de modo completamente relativista. Aloja-se, então, na mente da personagem, uma grande dúvida: quem era ele, na verdade? Para si próprio, ele era um, nenhum ou cem mil, não importa! Firme no propósito de desfazer as tantas imagens dele construídas e disseminadas, Vitangelo Moscarda inicia uma série de

\footnotetext{
12 PIRANDELLO, Luigi. O falecido Mattia Pascal, op. cit., p. 137.

13 BERMAN, Marshall. Tudo que é sólido desmancha no ar, op. cit., p. 17.

14 Ibidem, p. 25.
} 
atos insanos que deixam em polvorosa toda a cidade e, especialmente, sua esposa Dida. Inicialmente, ordena o despejo de um casal que há muito residia em uma casinha de sua propriedade. Após ouvir os insultos de seus concidadãos (Usurário! Usurário!), os quais assistiam ao pobre casal juntando seus poucos pertences na rua, debaixo de chuva, Moscarda faz, aos recém despejados, uma doação de uma casa de grande valor. De usurário, passa a ser chamado, então, de louco. A esposa foi-se embora sem a menor cerimônia após a perda do status de banqueiro rico do marido. Moscarda faz doações generosíssimas de seus bens, optando por morar em um albergue de mendigos e mentecaptos, onde termina seus dias.

\begin{abstract}
Nunca mais me olhei num espelho e nem me passa pela cabeça querer saber o que aconteceu com meu rosto e a minha aparência. Aquela que eu apresentava diante dos outros deve ter mudado muito, e de modo bastante cômico, a julgar pelo espanto e pelas risadas com que fui acolhido. [...] Nenhuma lembrança resta, hoje, do nome de ontem - ou do nome de hoje, amanhã. Se o nome é a coisa, se um nome é, em nós, o conceito de cada coisa situada fora de nós, e se, sem nome, não há conceito, ficando em nós a coisa como cega, indistinta e indefinida, então cada um grave aquele nome que tive entre os homens, entaIhando-o como um epitáfio sobre a fronte daquela imagem com que lhes apareci, deixando-a em paz e relegando-a ao esquecimento. Um nome não é mais do que isso: um epitáfio. Convém aos mortos, aos que concluíram. Eu estou vivo e sem conclusão. ${ }^{15}$
\end{abstract}

A tentativa desesperada de escapar das máscaras chega ao paroxismo em Um, nenhum e cem mil, narrativa que tematiza não somente o homem fragmentado, dividido em um caleidoscópio de imagens, mas também o fim das histórias de amor, da coerência social, da possibilidade de coexistência entre o Eu e o Outro. Ao assinalar tais rupturas, Pirandello reivindica outra forma de linguagem, aquela voltada para si mesma, aquela capaz de desarticular paradigmas, de questionar o próprio funcionamento interno, em outras palavras, uma linguagem autorreflexiva que subverte o conceito de mimesis e nega a representação do real como um dos objetivos da obra de arte. Desse modo, a antirrepresentação configura-se em um projeto estrutural que intenta desmascarar o processo criativo. Nesse sentido, as personagens de Pirandello encontram-se na encruzilhada entre representar e a impossibilidade de fazê-

\footnotetext{
${ }^{15}$ PIRANDELLO, Luigi. Um, nenhum e cem mil. Trad Maurício Santana Dias. São Paulo: Cosac Naify, 2010, p. 206-207.
} 
lo, pois estão inseridas em um sistema institucionalizado e hierarquicamente organizado.

Em Seis personagens à procura de um autor, talvez a mais conhecida peça de Pirandello, o jogo mimético é enfaticamente negado: no palco onde pretendem ensaiar os atores de uma peça, adentram seis personagens que reivindicam um autor que thes dê a possibilidade de representar. Todavia, a história já está pronta e, dela, os seis não abrem mão. Inicia-se, então, um longo diálogo entre personagens, diretor e atores, onde o processo criativo é desnudado diante dos olhos dos espectadores.

Já nas primeiras páginas da peça, está claro seu teor metaficcional, pois assim lemos:

[...] E o que é que o senhor quer que eu faça se não nos vem, da França, uma boa comédia e se estamos reduzidos a pôr em cena peças de Pirandello, que só os "iniciados" entendem, feitas, de propósito, de tal modo que não satisfaçam nem aos atores, nem aos críticos nem ao público? ... (Os atores riem) ${ }^{16}$

Essa fala do diretor, o qual se dirige a um ator que reclama por ter de usar um gorro de cozinheiro, seguida de outros diálogos, esclarece a proposta de Pirandello de romper com a mimesis e com as expectativas do público, acostumado a ver, nos palcos teatrais, a representação da vida como ela é, ou como parece ser. Nesse sentido, as personagens que reivindicam seu posto, que pretendem desvencilhar-se dos atores, que desejam elas mesmas representarem seus papeis, essas são verdadeiras personagens pirandellianas.

Vejamos o diálogo entre o Pai, uma das seis personagens, e o diretor, em Seis personagens à procura de um autor.

O DIRETOR: os senhores querem fazer graça?...

O PAI: Em absoluto! Que está dizendo, senhor? Ao contrário, trazemo-lhes um drama doloroso.

A ENTEADA: E podemos fazer a sua fortuna!

O DIRETOR: Façam-me o favor de ir embora! Não temos tempo a perder com loucos.

O PAI (ofendido, mas melífluo): Oh, senhor, sabe muito bem que a vida é cheia de infinitos absurdos, os quais, descaradamente, nem ao menos têm necessidade de parecer verossímeis. E sabe por que, senhor? Porque esses absurdos são verdadeiros. [...] Digo que, ao pensarmos nesses absurdos verdadeiros, que nem mesmo verossímeis nos parecem, vemos que a loucura consiste, justamente, no

\footnotetext{
${ }^{16}$ Idem, O falecido Mattia Pascal, op. cit., p. 356.
} 
oposto: em criar verossimilhanças que pareçam verdadeiras. E essa loucura [...] é a única razão de ser da profissão dos senhores.

O DIRETOR: [...] Acha que a nossa é uma profissão de loucos?...

O PAl: Hum! Fazer com que pareça verdadeiro o que não o é, sem necessidade... só por prazer. O ofício dos senhores não consiste em dar vida, na cena, a personagens imaginárias?

O DIRETOR: Pois eu the peço o favor de acreditar, meu caro senhor, que a profissão de ator é uma nobilíssima profissão! $\mathrm{E}$, se hoje em dia os senhores teatrólogos modernos só nos dão peças cretinas para representar, e fantoches em vez de homens, saiba que nos gloriamos de ter dado vida, aqui, sobre essas tábuas, a obras imortais!

O PAI: É isso mesmo![...] Dar vida a seres vivos, mais vivos que aqueles que respiram e vestem roupas! Menos reais, talvez, porém mais verdadeiros. Somos da mesma opinião.

$[\ldots]$

O DIRETOR: E o senhor, com essas outras pessoas em volta, nasceu personagem?

O PAl: Exatamente. E vivos, como nos vê.

( $O$ diretor e os atores desatam a rir, como se tratasse de uma brincadeira.) $)^{17}$

Nas palavras do Pai encontra-se a síntese do que as personagens representam na obra de Pirandello: sua realidade pode ser menos real, mas é certamente mais verdadeira. Isso ocorre pelo simples fato de que, de acordo com o siciliano, não há, no mundo, uma realidade exclusiva ou definitiva, mas múltiplas possibilidades e perspectivas. A realidade, dessa forma, entra em colapso, juntamente com a noção de verdade, como afirma Raymond Williams em Tragédia moderna:

Podemos construir, para nós mesmos, uma ilusão e podemos temporariamente entrelaçá-la à ilusão de outra pessoa. Mas, enquanto a vida continua, o entrelaçamento é ameaçado, e tanto a pressão do outro, representando a sua própria ilusão, quanto ainda a sua distância, a impossibilidade de alcançá-lo verdadeiramente, são vivenciadas de modo trágico. ${ }^{18}$

Assim sendo, a personagem que se distancia do humano e se reconhece unicamente como personagem coloca-se acima do homem que, desprovido de uma identidade coesa e de uma realidade, busca, incessantemente, representar papeis, vestir máscaras, com a ingênua esperança de que pareçam

\footnotetext{
${ }^{17}$ Ibidem, p. 361-364.

${ }^{18}$ WILLIAMS, Raymond. Tragédia moderna. Tradução de Betina Bichof. São Paulo: Cosac Naify, 2002, p. 197.
} 
reais. Em outras palavras, a personagem é dotada de uma verdade que o homem não possui. Desse modo, o autor radicaliza e cria, em toda sua obra, uma espécie de alegoria negativa da impossibilidade de comunicação do indivíduo que vive em uma sociedade fundamentalmente ilusória e carente, a sociedade moderna. Verdade? Somente a personagem possui.

Em $A$ desumanização da arte ${ }^{19}$, José Ortega y Gasset, ao referir-se à música, à literatura e ao teatro, explica que durante o século XIX, os artistas reduziram ao mínimo os elementos estritamente estéticos, fazendo com que a arte consistisse, quase que na sua totalidade, na representação de realidades humanas. Em outras palavras, para Ortega $Y$ Gasset, toda a arte era realista, cópia da vida, sendo que, para com ela deleitar-se, era necessário somente possuir alguma sensibilidade humana. Talvez seja por isso, afirma o crítico espanhol, que:

a arte do século XIX tenha sido tão popular: está feita para a massa indiferenciada na proporção em que não é arte, mas sim extrato da vida. Lembre-se de que em todas as épocas em que existiram dois diferentes tipos de arte, um para minorias e outro para a maioria, esta última foi sempre realista. ${ }^{20}$

Contudo, a arte nova, nascida no final do século XIX e início do XX, que ultrapassou as barreiras da representação é, para Ortega $Y$ Gasset, aquela que se propôs a deformar a realidade, romper com seu aspecto humano, confrontar o espectador, intimidá-lo, desafiá-lo. Tal tarefa, aparentemente fácil, é de uma complexidade gigantesca, pois "a realidade espreita constantemente o artista para impedir sua evasão. Quanta astúcia pressupõe a fuga genial!”21 De acordo com o crítico espanhol, Pirandello foi um dos grandes artistas do final do século XIX que obrigou o povo, o qual queria ser reconhecido como "toda" a sociedade, a enxergar-se como o que é, apenas povo, "mero ingrediente [...] da estrutura social, inerte matéria do processo histórico, fator secundário do cosmos espiritual." 22 Para tanto, Pirandello renegou o mundo exterior, aquele conhecido pelo povo inculto, submergindo no mundo obscuro da arte, exclusivamente.

\footnotetext{
${ }^{19}$ ORTEGA Y GASSET, José. A desumanização da arte. Trad. Vicente Cechelero. 6. ed. São Paulo: Cortez, 2008, p. 28.

${ }^{20}$ Ibidem, p. 29.

${ }^{21}$ Ibidem, p. 43.

${ }^{22}$ Ibidem, p. 23.
} 
Não obstante a rusticidade e a grosseria contínua de sua matéria, foi a obra de Pirandello, Seis personagens à procura de um autor, talvez a única nestes últimos tempos que provoca a meditação do aficionado na estética do drama. É ela um claro exemplo dessa inversão do tema artístico que procuro descrever. O teatro tradicional nos propõe que em suas personagens vejamos pessoas e nos espaventos daquelas a expressão de um drama "humano". Aqui [em Pirandello], pelo contrário, se consegue interessar-nos por umas personagens como tais personagens; ou seja, como ideias ou puros esquemas. Caberia afirmar que esse é o primeiro "drama de ideias", rigorosamente falando, que se compôs. Os que antes se chamavam assim não eram tais dramas de ideias, mas sim dramas entre pseudopessoas que simbolizam ideias. ${ }^{23}$

Assim sendo, a proposta de Pirandello vai de encontro às expectativas do público, o qual procura o drama humano na obra de arte, drama esse constantemente desvirtuado, ironizado ou simplesmente excluído, pois a ruptura, a subversão, o rasgo, são os reflexos fundamentais da prática discursiva pirandelliana. Seu teatro é "sobre" a representação, não "de" ou "para" a representação, sendo que o discurso se volta a si mesmo, exclusivamente. Entretanto, ao mesmo tempo em que nega a realidade da vida, exterior ao texto, Pirandello exacerba a ideia da impossibilidade da representação de uma existência alienada utilizando-se de personagens campesinos, funcionários públicos medíocres, ociosos, pessoas comuns, com alguma deformidade física, inclusive. Tal aproximação com a vida como ela é representa justamente a negação dessa vida proposta por Pirandello. Em outras palavras: para fugir do homem comum e da tentativa de representá-lo, a estratégia é justamente colocá-lo em cena, menosprezá-lo, ridicularizá-lo, postura que vai ao encontro de uma sistemática artística frequente no início do século XX. Nesse período, assistimos a uma considerável transformação da personagem romanesca e teatral, a chamada "crise da personagem". Para entendermos o significado dessa expressão, é interessante partirmos das considerações de um grande crítico literário italiano chamado Giacomo de Debenedetti ${ }^{24}$, o qual escreve:

Appena ci si mette a leggere i romanzi moderni si è colpiti da un fatto abbastanza sconcertante. Dal ritratto dei personaggi scompare, quasi senza eccezione, ogni vestigio di bellezza fisica, specialmente nella faccia, cioè nella parte più espressiva della persona. [...] In breve, col finire della narrativa naturalista [...] comincia nel romanzo e nel racconto l'invasione vittoriosa dei brutti, che a

\footnotetext{
23 Ibidem, p. 65-66.

${ }^{24}$ DEBENEDETTI, Giacomo de. Il personaggio uomo. Milano: Garzanti, 1988.
} 
non lungo andare occuperanno tutto il territorio. [...] Per rimanere nell'ambito italiano, si guardino i personaggi di Pirandello e di Federigo Tozzi, i due veri iniziatori del romanzo moderno in Italia. A mettere insieme i visi e le figure di quella gente, si ricava poco meno che un'adunata da moderna Corte dei Miracoli: un repertorio di rappresentanti dello squallido, dello scostante, dello scontroso, dell'inameno, dello scombinato, del repulsivo. [...] Pirandello ha dunque intuito [...] l'eziologia dell'affezione deformante che interessa prima di tutto $i$ tratti facciali, imprime sul viso una facies 1 che lo dissesta e gli dà un'espressione disofferenza. [...] Comunque, l'agente patogeno è l'Altro, che fa sentire la sua presenza dentro l'lo, se vogliamo usare la terminologia di Rimbaud. ${ }^{25}$

A consideração de Debenedetti parece, em um primeiro momento, limitarse a um nível exclusivamente estético: a beleza física da personagem. Todavia, o conceito pode ser ampliado para um plano menos material, atingindo as esferas ética, estética e moral. É fato que, especialmente a partir dos anos 1900, já não é mais possível tratar a personagem se não como um ser fraturado e problemático, contrário ao equilibrado, sereno e belo sujeito da arte antiga. Essas figuras não encontram, raríssimas são as exceções, finais felizes na poética pirandelliana. Ao contrário, nascem, vivem e morrem sob as pesadas botas da sociedade que jamais as perdoa pela sua mediocridade.

De maneira globalizante, a morte do homem livre é fortemente assinalada na obra de Pirandello. Todavia, é por intermédio de personagens sicilianas provincianas, tacanhas, que tal morte é reforçada, de forma particularizada. Nesse sentido, a proposta de Pirandello é global e particular ao mesmo tempo, pois tende a certa universalidade, sendo testemunho de uma sociedade em específico: a da Sicília. Mesmo afirmando que o valor de Pirandello é mais cultural do que estético, Gramsci compreendeu bem essa característica do discurso pirandelliano. Para o filósofo italiano, Pirandello:

\footnotetext{
25 "Assim que começamos a ler romances modernos, somos atingidos por um fato bastante impressionante. Do retrato dos personagens desaparece, quase sem exceção, cada vestígio da beleza física, especialmente no rosto, que é a parte mais expressiva de uma pessoa. [...] Em suma, com o fim da narrativa naturalista [...] começa no romance e no conto a invasão vitoriosa do feio, que a curto prazo ocupa todo o território. [...] Para permanecer dentro do âmbito italiano, observemos os personagens de Pirandello e Federigo Tozzi, os dois verdadeiros iniciadores do romance moderno italiano. Ao colocar juntos os rostos e figuras daquela gente, obtinha-se pouco menos do que um encontro da moderna corte dos milagres: um repertório de representantes do esquálido, o hostil, o mal-humorado, o transtornado, o repulsivo. [...] Pirandello então percebeu [...] a etiologia da doença deformante que afeta em primeiro lugar os traços faciais, dá ao rosto uma aparência que desestabiliza e dáIhe uma expressão de sofrimento [...]. No entanto, o patógeno é o Outro, o que faz sentir a sua presença no eu, se quisermos usar a terminologia de Rimbaud." Tradução nossa.
} 
é criticamente um "aldeão" siciliano que adquiriu certas características nacionais e outras europeias, mas que sente em si mesmo esses três elementos de civilização como justapostos e contraditórios. Dessa experiência, veio-lhe a atitude de observar as contradições na personalidade dos outros e, posteriormente, também aquela de ver o drama da vida como o drama dessas contradições. ${ }^{26}$

Gramsci pontua, ainda, que Pirandello contribuiu imensamente para desprovincianizar o homem italiano, despertando nele um senso crítico capaz de transcender a atitude melodramática tradicional dos anos 800. Entretanto, o fez por intermédio de personagens como Mattia Pascal e Vitangelo Moscarda, sujeitos alienados, sem saída diante da história, das forças sociais e da avassaladora locomotiva moderna. Não é possível determinar uma gramática ou um sistema discursivo da modernidade, mas se pode encontrar certa lógica no teatro e na literatura modernos com base nas palavras de Baudelaire: "A modernidade é o transitório, o efêmero, o contingente, é a metade da arte, sendo a outra metade o eterno e o imutável". ${ }^{27}$ Nesse sentido, a forma pirandelliana de captar o transitório consiste na insistência em abordar o descentramento do Eu e da obra, o que ocorre mediante a desarmonia, os finais inconclusivos e o mal estar presentes em muitos de seus textos. Dessa forma, nenhuma relação é duradoura ou permanente em Pirandello, tudo é transitório, temporário, fugaz, assim como a vida moderna. Vida que, para o siciliano, pode ser muito mais inverossímel e sem sentido do que a arte.

É justamente a busca do sentido da vida que move Pirandello em uma época em que, segundo Weber, citado por Berman, os homens não passam de "especialistas sem espírito, sensualistas sem coração; e essa nulidade caiu na armadilha de julgar que atingiu um nível de desenvolvimento jamais sonhado antes pela espécie humana". ${ }^{28}$ Wladimir Krysinski, em /l paradigma inquieto: Pirandello e lo spazio comparativo della modernita ${ }^{29}$, assinala que a inquietude de Pirandello se insere no quadro de um gosto artístico que, no início do século XX, era comum a alguns grandes criadores, como Joyce, H. James, V. Woolf, Musil, entre outros, os quais sinalizavam para a morte do homem liberal.

${ }^{26}$ GRAMSCI, Antonio. Literatura e vida nacional. Trad. Carlos Nelson Coutinho. Rio de Janeiro: Civilização Brasileira, 1968, p. 58.

${ }^{27}$ BAUDELAIRE, Charles. O pintor da vida moderna. In: COELHO, Teixeira. (Org.). A modernidade de Baudelaire. Trad: Suely Cassal. Rio de Janeiro: Paz e Terra, 1988, p. 174.

${ }^{28}$ BERMAN, Marshall. Tudo que é sólido desmancha no ar, op. cit., p. 26.

${ }^{29}$ KRYSINSKI, Wladimir. Il paradigma inquieto. Pirandello e lo spazio comparativo della modernità. Trad. Corrado Donati. Roma: Edizioni Scientifiche Italiane, 1988, p. 33. 
Segundo Krysinski, o escritor austríaco Robert Musil foi, sem dúvida, o criador e o analista mais sutil e o que melhor articulou esse processo, especialmente em Uomo senza qualità. Nesse romance, Musil diagnostica uma misteriosa doença da época: a vida europeia não coincidia com a ideologia europeia.

O professor Walter Moser, da Universidade de Otawa, é citado por Krysinski como o mais pontual examinador da questão da morte do homem liberal na obra de Musil. De acordo com Moser, Musil ${ }^{30}$ :

affronta a più riprese l'esperienza che priva l'individuo delle qualità in virtù delle quali può erigersi nella funzione di soggetto: razionalità, autonomia, responsabilità, stabilità [...] La perdita dei suoi attributi di uomo liberale si intensifica fino al loro annullamento: l'individuo [è] di colpo ridotto al suo compito elementare: proteggere la stirpe. $^{31}$

Para o professor polonês Wladimir Krysinski, essa fórmula pode definir perfeitamente o universo da dissolução do Eu de Pirandello, pois, em toda sua obra, encontram-se temáticas e discursos que correspondem à perda daquilo que Musil chama "função do eu" e "conceito de eu". Nesse sentido, a poética pirandelliana multiplica as perspectivas, sem que nenhuma seja a verdadeira ou a central, aproximando-se do que assegurava Nietzsche:

O mundo é cognoscível; mas este é interpretável de modos diversos, e não existe nele um sentido, mas inumeráveis sentidos. "Perspectivismo". São os nossos desejos que interpretam o mundo: os nossos instintos com seus prós e contras. $^{32}$

Não seria equivocado afirmar que o perspectivismo de Nietzsche se aproxima ao de Pirandello, tão bem exemplificado em Um, nenhum e cem mil, romance onde um determinado sujeito se choca com a própria imagem refletida no espelho, a qual também impacta com os tantos outros conceitos a ele atribuídos pelos outros. Quem era Vitangelo Moscarda? Um? Nenhum? Cem mil.

Encenada pela primeira vez em 1917, Assim é (se lhe parece), uma adaptação que o próprio Pirandello produziu de uma novela escrita dois anos antes,

${ }^{30}$ Ibidem, p. 34.

31 "enfrenta repetidamente a experiência que priva o indivíduo das qualidades pelas quais ele pode manter-se erguido em sua função de sujeito: racionalidade, autonomia, responsabilidade, estabilidade [...] A perda de seus atributos de homem liberal se intensifica até o anulamento: o indivíduo [é], de repente, reduzido à sua tarefa elementar: proteger a linhagem." Tradução nossa.

${ }^{32}$ NIETZSCHE, Friedrich. Fragmentos póstumos: 1855/1886. In: Textos didáticos. Campinas, n. 22, abr. 1996, p. 16-17. 
intitulada $A$ senhora Frola e o senhor Ponza, traz a história de um grupo de curiosos e palpiteiros de uma cidadezinha do interior da Sicília que dedica boa parte de seu tempo para desvendar os mistérios da família que acabara de chegar: senhor e senhora Ponza, e a sogra, senhora Frola. O que desperta a curiosidade da população do lugarejo é o fato de a pequena família não viver sob o mesmo teto. Senhor Ponza e sua esposa residem em uma casa, enquanto a sogra vive em outra. Genro e sogra, todavia, têm versões opostas para o fato. Apesar de morarem em casas separadas, a senhora Frola visita a filha diariamente, mas apenas à distância. Ela diz que em razão da possessividade do genro, Sr. Ponza, mãe e filha não podem ter contatos mais íntimos. A versão do genro, entretanto, é que a sogra tem problemas psiquiátricos, não aceita o fato de que sua filha verdadeira morrera há quatro anos. Em função disso, senhor Ponza pede que sua segunda esposa, a qual só aparece ao final da peça, se passe pela filha da senhora Frola, represente esse papel.

Essas distintas versões do fato aguçam a curiosidade dos moradores, que promovem um verdadeiro tribunal informal para chegar, sem sucesso, à verdade. Frente à impossibilidade de decidir quem seria o louco da trama, os pacatos cidadãos da cidade entram num estado de histeria coletiva e instauram um verdadeiro interrogatório a fim de extrair a verdade dos forasteiros. Genro e sogra, em função disso, ameaçam abandonar a cidade. É então que, intimada a comparecer diante de todos, ao final do terceiro ato, a jovem senhora Ponza surge no gabinete do prefeito, vestida de preto e com um véu espesso que lhe oculta a face.

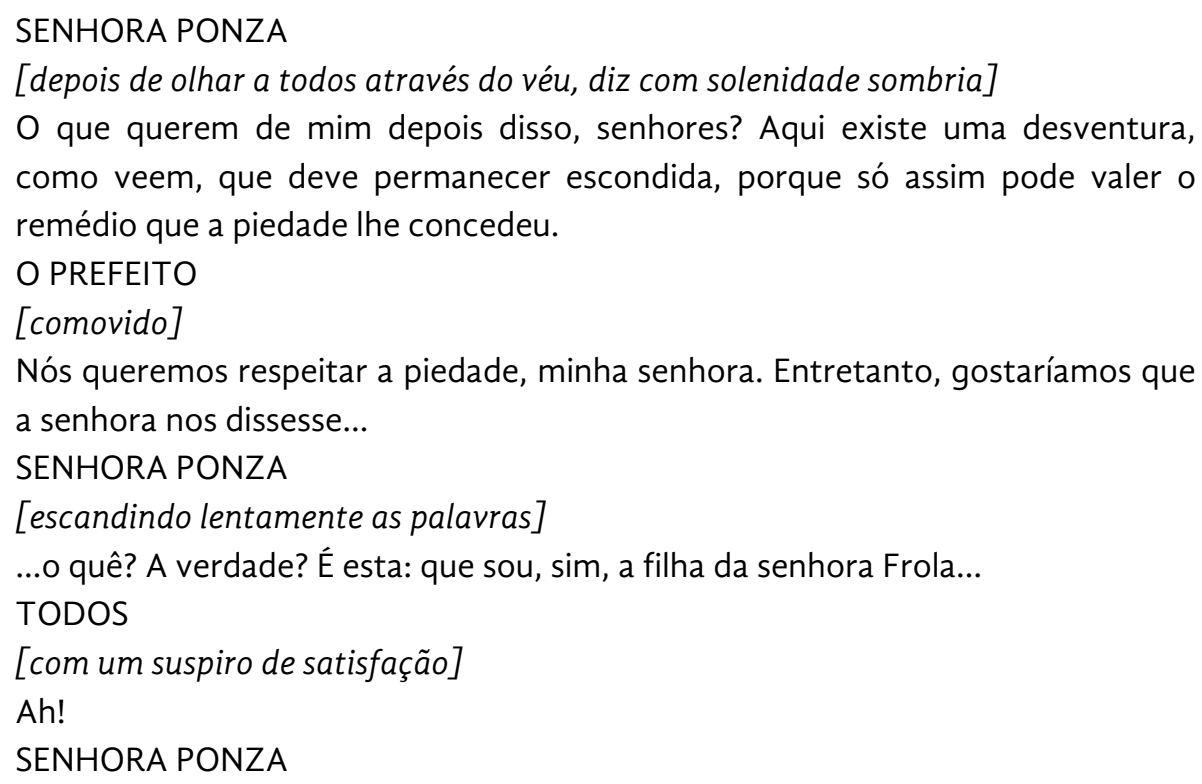


[logo em seguida, com o mesmo tom de antes]

...e a segunda esposa do senhor Ponza...

TODOS

Oh! Como assim?

SENHORA PONZA

...sim, e para mim nenhuma, nenhuma!

O PREFEITO

Ah, não, senhora. Para si própria, a senhora deve ser uma ou outra!

SENHORA PONZA

Não senhores. Para mim, sou aquela que se crê que eu seja.

[olha para todos através do véu e se retira. Silêncio] ${ }^{33}$

Prevalece, em Assim é (se lhe parece), um dos temas mais caros a Pirandello: a dúvida acerca da sanidade, da verdade e a aposta na incapacidade do ser humano de conhecer a realidade. Não há, para o escritor siciliano, uma verdade absoluta, mas incontáveis perspectivas, estritamente relacionadas à individualidade de cada um. Como cada homem vê-se obrigado a vestir máscaras e assumir papeis, de forma ininterrupta e compulsória, acaba sendo nenhum. Ou, parafraseando a senhora Ponza, é aquilo no qual os outros acreditam.

A crise existencial do homem moderno, portanto, torna-se uma constante em Pirandello, o qual não se ajusta ao pensamento até certo ponto positivo de alguns grandes críticos da modernidade do século XIX que, segundo Berman, compreendem que:

a tecnologia moderna e a organização social condicionaram o destino do homem. Porém, todos eles acreditavam que os homens modernos tinham capacidade não só de compreender esse destino, mas também de, tendo-o compreendido, combatê-lo. Assim, mesmo em meio a um presente tão desafortunado, eles poderiam imaginar uma brecha para o futuro. ${ }^{34}$

Para as personagens de Pirandello, as quais traduzem a inquietude, o medo, as incertezas e a angústia do homem moderno, o mundo é algo sem controle e sem solução, onde vivem e se jogam sempre para perder. Suas criaturas são sempre seres fraturados, divididos, sobreviventes de uma catástrofe chamada modernidade.

\footnotetext{
${ }^{33}$ PIRANDELLO, Luigi. Assim é (se lhe parece). Trad. Sergio N. Melo. São Paulo: Tordesilhas, 2011, p. 173-174.

${ }^{34}$ BERMAN, Marshall. Tudo que é sólido desmancha no ar, op. cit., p. 25.
} 